This document is published in:

The Electricity Journal (2002), 15 (7), 72-81.

DOI: http://dx.doi.org/10.1016/S1040-6190(02)00347-0

(C) 2002 Elsevier Science Inc. 


\section{Modeling Electricity Auctions}

The recent debates over discriminatory versus

uniform-price auctions in the U.K. and elsewhere have revealed an incomplete understanding of the limitations of some popular auction models when applied to real-world electricity markets. This has led some regulatory authorities to prefer discriminatory auctions on the basis of reasoning from models which are not directly applicable to any existing electricity market. Vickrey auctions, although often recommended by economists, have also been ignored in these debates.

Natalia Fabra, Nils-Henrik von der Fehr, and David Harbord

\section{Introduction}

Electricity wholesale markets differ in numerous dimensions, but until recently all have been organized as uniform first-price auctions. Recent experience-and the perceived poor performance-of some decentralized electricity markets, however, has led certain regulatory authorities to consider adopting new auction designs. In England and Wales, a major overhaul of the electricity trading arrangements introduced in 1990 has recently taken place, and among the reforms implemented in March 2001, a discriminatory or "pay-as-bid" auction format has been adopted. The British regulatory authorities believed that uniform auctions are more subject to strategic manipulation by large traders than are discriminatory auctions, and expected the new market design to yield 
substantial reductions in wholesale electricity prices. ${ }^{1}$

S imilarly, the now-defunct $\mathcal{O}$ California Power Exchange last year commissioned a report by leading auction theorists on the advisability of a switch to a discriminatory auction format for the PX' day ahead market, due to the increasing incidence of price spikes in both on- and off-peak periods. Again, the suggestion was that a discriminatory auction might curtail the abuses of market power to which the market had evidently been subject. $^{2}$

It is well-known among auction theorists that discriminatory auctions are not generally superior to uniform auctions. Both types of auction are commonly used in financial and other markets, and there is now a voluminous economic literature devoted to their study. ${ }^{3}$ In multiunit settings the comparison between these two auction forms is particularly complex. Neither theory nor empirical evidence tell us that discriminatory auctions perform better than uniform auctions in markets such as those for electricity, although this has now become controversial.

Wolfram, ${ }^{4}$ for instance, has argued in favor of uniform auctions for electricity, and Rassenti, Smith, and Wilson ${ }^{5}$ cite experimental evidence which suggests that discriminatory auctions may reduce volatility (i.e., price spikes), but at the expense of higher average prices. Other authors have come to opposite conclusions. Federico and Rahman $^{6}$ find theoretical evidence in favor of discriminatory auctions, at least for the polar cases of perfect competition and monopoly, while Klemperer ${ }^{7}$ suggests that discriminatory auctions might be less subject to "implicit collusion." Kahn, Cramton, Porter, and Tabors, 8 on the other hand, reject outright the idea that switching to a discriminatory auction will result in

It is well-known among auction theorists that discriminatory auctions are not generally superior to uniform auctions.

greater competition or lower prices.

W been focused on the advantages or disadvantages of uniform versus discriminatory auctions, among economists Vickrey auctions are often favored. Vickrey auctions make "truthful" bidding, e.g., bidding at marginal cost, a weakly dominant strategy for firms, and hence result in least-cost production, or dispatch efficiency. This comes at a cost, since firms with market power need to be paid the opportunity costs of their bids, and these payments can be large. ${ }^{9}$ Vickrey auctions in markets such as those for electricity have to date received relatively little detailed analysis, however. ${ }^{10}$

In a recent paper we addressed this electricity auction design issue in a series of models which represent some of the key features of decentralized electricity markets, albeit within a simplified framework. ${ }^{11} \mathrm{We}$ characterized equilibrium market outcomes in a discrete, multi-unit auction model for uniform, discriminatory, and Vickrey electricity auctions under a variety of assumptions concerning firms' costs and capacities, demand elasticities, the auction bid format and the number of suppliers in the market. Our purpose was to gain an improved understanding of how these different auction formats affect suppliers' bidding behavior, the degree of competition, and overall welfare in decentralized electricity markets.

Not surprisingly, we found that the welfare ranking of the auction types is inherently ambiguous. If the regulator is solely concerned with productive efficiency, then the Vickrey auction should always be chosen, as it guarantees efficiency independently of industry and market data. If, on the other hand, the regulator is solely concerned with the maximization of consumer surplus, then a uniform auction should probably never be chosen, as it is typically outperformed by the discriminatory auction, and 
in some cases by the Vickrey auction.

F or more general regulatory 1 preferences the ranking is uncertain. ${ }^{12}$ For some specifications of demand, costs, and firms' capacities, the discriminatory auction dominates the uniform auction on both efficiency and consumer surplus criteria. In other scenarios the reverse ranking can be shown to (weakly) hold. Hence, if the regulator is restricted to a choice between discriminatory and uniform auctions, this should be viewed as an empirical question that depends upon the nature of demand, market structure, and the relative efficiencies of firms. Our analysis provides no support, however, for the presumption of some regulatory authorities that by changing the auction format from uniform to discriminatory a significant improvement in market performance can be achieved.

The purpose of this article is not to describe this equilibrium analysis in any detail. Rather we wish to explain our choice of models, for this has also recently become controversial, and it is critically important to policy discussions. Indeed, some regulatory authorities appear to have come to prefer discriminatory over uniformprice auctions on the basis of reasoning from auction models that are not directly applicable to any existing electricity market. We also discuss some of the pros and cons of using Vickrey auctions, which in our view have received too little attention in recent debates.

\section{Modeling Electricity Auctions}

As auction theorist Paul Klemperer has recently noted, although it was not initially well-understood that deregulated electricity markets are best described and analyzed as auctions, this is now

\section{In our view, Vickrey auctions have received too little attention in recent debates.}

uncontroversial. With the exception of the new discriminatory auction format adopted in England and Wales, all electricity markets created to date have been organized as first-price, multiunit auctions. Competition in these markets occurs by suppliers submitting bids which specify the minimum prices at which they are willing to supply energy, and the amount of capacity available at each price. On the basis of these bids an industry supply curve is constructed, which together with a forecast of demand determines which generating units will be dispatched in any particular period. In uniform, or first-price, electricity auctions, market prices are determined by the bid price of the marginal accepted unit. In discriminatory auctions, such as the England and Wales balancing market, suppliers are paid their bids, while consumers pay a (weighted) average of the accepted bids.

Within this general framework there is huge variation in auction designs, most of which can be safely ignored for our current purposes. Three features of electricity auctions are crucial to any analysis, however. First, all electricity auctions limit the number of bids that may be submitted by any supplier to a small number. For example, in the original market design in England and Wales, generators were permitted only three incremental bid prices per unit of capacity, while in the Spanish electricity market generators may submit up to 25 price-quantity pairs. This means that all electricity auctions are discrete multi-unit auctions rather than continuous "share auctions" or auctions for perfectly divisible goods. This distinction is important because the analysis of auctions with discrete (i.e., step) bid functions differs in significant ways from that for auctions with continuous supply or demand schedules. We expand on this point immediately below.

Secondly, electricity auctions differ in the duration of suppliers' bids. In Australia and Argentina (and in the original U.K. market), generator bids are "long-lived" so that a single step-bid function remains valid for an extended 
period during which demand varies. ${ }^{13}$ In contrast, in the Spanish, Nordic, and (now defunct) California markets, bids are "short-lived," and last for a single market period only. In Australia and Argentina, although the value of demand in any period may be known with a high degree of certainty, suppliers' bids are constant over numerous periods during which demand fluctuates. Thus, from the point of view of bidders, demand may be viewed as being either stochastic or variable. ${ }^{14}$ Conversely, when bids are short-lived, demand in any period will be known with certainty, i.e., fixed, before bids are submitted.

$\mp$ inally, suppliers in electricity binding capacity constraints, which means that in many periods there will be no excess supply when the capacity of a single firm is taken out of the system. While much has been made of this fact in recent regulatory inquiries and policy discussions, it has been ignored in some theoretical discussions, despite its strong implications for the analysis of equilibria in any auction format.

These three characteristics of electricity auctions have been important in determining our choice of models, and they are also key to understanding the related literature. Most analyses of electricity auctions to date have adopted one of two possible modeling approaches: the continuous "share auction" or "supply function" approach pio- neered by Wilson, Back, and Zender and Klemperer and Meyer, and applied to the British electricity market by Green and Newbery (1992), ${ }^{15}$ or the discrete, multi-unit auction approach, first applied to electricity markets by von der Fehr and Harbord (1993). ${ }^{16}$ The predictions of these models differ significantly, however, and where they do careful interpretation of the results is required. In the

The predictions of the two major modeling approaches differ significantly, and where they do careful interpretation is required.

remainder of this article we discuss the comparison of uniform and discriminatory auctions based on these (and related) modeling approaches, and then discuss the much less extensive literature on Vickrey electricity auctions.

\section{Uniform or Discriminatory?}

\section{A. Markets with short-lived bids}

For electricity auctions with short-lived bids, to a first approximation, demand in each period will be known with certainty by all market participants before bids are submitted. Hence, these markets are best analyzed as auctions with fixed, or deterministic, demand. As noted by Klemperer, ${ }^{17}$ if such markets are treated as auctions for "infinitely divisible quantities of homogeneous units," then even in the absence of binding capacity constraints, "collusive-like" equilibria can arise, resulting in very high profits and prices. Such outcomes can be supported in a uniform auction because firms are concerned with only a single point on their (continuous) supply curves, the point corresponding to the market-clearing price, and the rest of the supply curve can be used to inhibit competition from the other suppliers.

- or example, if a supplier curve, the residual demand curve facing his rivals will also be steep. A steep residual demand curve implies that the opportunity cost of capturing an increment in supply beyond the supplier's collusive allocation is high. In this way artificially high prices can be supported in equilibrium. These strategies are costless in a uniform auction because the low inframarginal bids used to support the equilibria are payoff-irrelevant, and never received by the bidder. ${ }^{18}$

In a discriminatory auction, on the other hand, any price bid below the market-clearing price will be paid to the bidder. 
This means that a supplier will care about its entire supply curve, rather than just a single point on it, effectively restricting the set of strategies that may be played in equilibrium. In the absence of pay-off irrelevant bids, the "collusive-like" equilibria of the uniform auction cannot be implemented.

K lemperer (2001) has the collusive equilibria of the continuous uniform auction are one reason that the regulatory authorities in Britain decided to adopt a discriminatory auction format:

Uniform-price auctions are more vulnerable than ... discriminatory auctions to collusion .... In a uniform-price auction ... bidders can tacitly agree to divide up the market at a very favorable price for themselves by each bidding extremely aggressively for smaller quantities than its collusive share, thus deterring other bidders from bidding for more .... The U.K. electricity regulator believes this market has fallen prey to exactly this kind of implicit collusion. ... By contrast, implicit collusion is harder in a discriminatory auction. Partly for this reason the U.K. regulator has proposed a set of New Electricity Trading Arrangements (NETA) that will replace the uniform-price auction by an exchange market followed by a discriminatory auction ....

Electricity auctions are not continuous share auctions, however, and the equilibrium outcomes of the continuous model differ significantly from those of the discrete, multi-unit model. In particular, where the uniform auction with continuous bid functions yields a continuum of pure-strategy equilibria, some of which are "collusive" in the sense described above, the discrete multi-unit auction model predicts a unique, Bertrand-like equilibrium. This is because in the continuous auction, as noted, suppliers can bid in very steep supply functions which eliminate

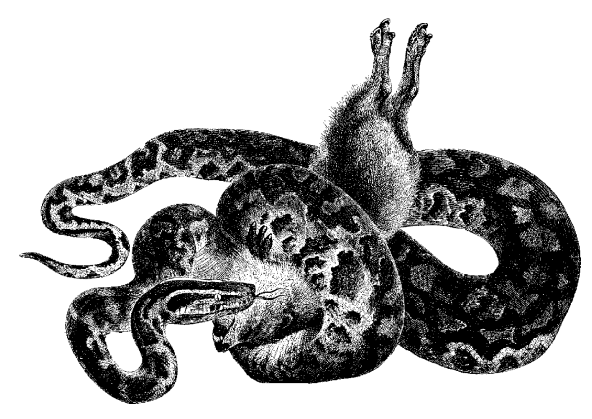

a rival's incentive to bid more aggressively. ${ }^{19}$ Discreteness in the bid functions rules this out, however. When suppliers are limited to a finite number of price-quantity bids, a positive increment in output can always be obtained by just slightly undercutting the price of a rival's unit. Since this "quantity effect" outweighs the "price effect," the collusivelike equilibria found in the continuous auction cannot be implemented.

Because this remains true in the limit, as we allow the bid-step size to become infinitesimal, it cannot even be argued that the continuous share auction model is a valid approximation to the discrete model for small enough bid-steps. This means that the collusive-like equilibria of the share auction model are probably irrelevant for policy prescription in electricity markets, and should not be used to diagnose competition problems. They are derived from an auction model which simply does not apply.

This point was first alluded to in von der Fehr and Harbord (1993), and has now been made independently, and particularly clearly, by Nyborg. ${ }^{20}$ He shows that the collusive equilibria of the Wilson, Back, and Zender models are eliminated when bidders can only make a finite number of bids (or there is a quantity multiple), and instead Bertrand-like price competition is induced. ${ }^{21}$ Indeed, Nyborg suggests that this may explain the prevalence of uniform auctions, despite the theoretical warnings of severe underpricing, as well as the ambiguous conclusions reached by the U.S. Treasury experiments. $^{22}$

\section{B. Markets with long-lived bids}

When suppliers' bids are longlived, i.e., stay constant over many separate market periods, then demand is best treated as being variable, or uncertain, from a supplier's point of view, rather than fixed and known with certainty at the time bids are submitted. The relevant version of the continuous auction is then Klemperer and Meyer's (1989) "supply function" equilibrium 
model..$^{23}$ The addition of demand variability or uncertainty can reduce the set of equilibria in the auction significantly, since there are fewer payoff-irrelevant bids that can be used to support "collusive-like" equilibria. ${ }^{24}$ As shown by Klemperer and Meyer (1989), equilibria in the supply function model will typically lie between the perfectly competitive and Cournot market outcomes.

$\mathrm{T}$ he reduction in the number of equilibria in the continuous model also reduces the extent to which the continuous and discrete multi-unit auction models disagree. Nevertheless, the two models still diverge in significant ways. In the first place, where the supply function model yields a continuum of pure-strategy equilibria, some of which involve prices well above marginal costs of any firm, the discrete multi-unit model again predicts a unique Bertrandlike market outcome. ${ }^{25}$ And secondly, in the discrete multiunit auction with capacity constraints, there will frequently be no pure strategy equilibria at all. ${ }^{26}$ The models thus differ both in their description of equilibrium bidding behavior, and in the predicted market outcomes. Again, since the equilibria of the discrete model do not converge to the equilibria of the continuous supply function model as we let the size of the bid-step become small, use of the supply function model cannot be justified by arguing that it approximates the discrete multi-unit model in the limit.

\section{Comment}

Equilibrium predictions of continuous share auction, or supply function, models differ significantly from those derived from discrete multi-unit models. Since in all electricity auctions

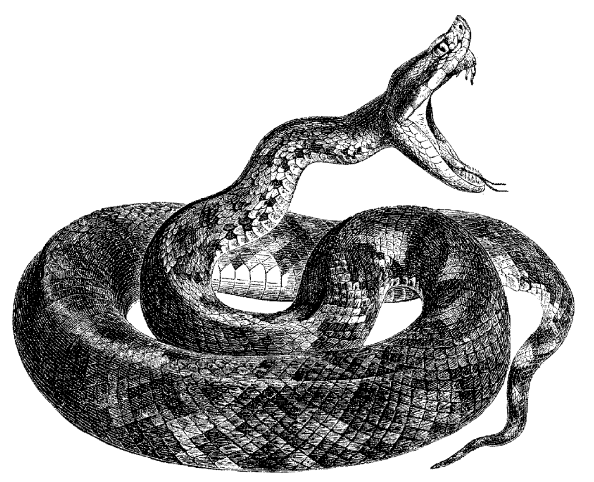

suppliers are limited to a small (i.e., finite) number of bids, this means that the results from the supply function approach must be treated with considerable care, and may frequently be inapplicable. This fact has not received the recognition it deserves in the existing literature, and is especially important when evaluating the efficiency of different auction formats.

$\bigcirc$ areful theoretical work and experiments have so far yielded no strong reasons for preferring discriminatory to uniform price auctions for electricity. Application of the continuous supply function model may well have led the British regulatory authorities astray on this issue however, and at considerable potential cost in terms of regulatory resources and market performance.

\section{Other literature}

Kahn, Cramton, Porter, and Tabors have also compared uniform and discriminatory auctions for electricity, based on results from the general auction literature. $^{27}$ In their report for the California PX (see Kahn et al., 2001) they concluded that the proposed shift from a uniform to a discriminatory auction was illadvised, and unlikely to result in lower electricity prices. In particular:

The immediate consequence would be a radical change in bidding behavior that would: (i) forestall the anticipated savings; (ii) introduce unmeasurable inefficiencies in the dispatch of power and impose new costs on generating companies, which would inevitably tend to increase rather than decrease average prices; (iii) tend to weaken the competition in generation ...; and (iv) impede... the expansion of capacity that, along with intensified demand-side response, is the only fundamental remedy for the recent poor performance of electricity markets in California.

Kahn et al. (2001) argued that in a competitive electricity market, in a uniform auction, each generating company would have strong incentives to bid at marginal (avoidable) cost, hence ensuring both productive and allocative efficiency. In a discriminatory auction, on the other hand, although this may 
theoretically still be the case, bidders' attempts to predict the marginal accepted bid will inevitably lead to forecasting errors and hence to dispatch inefficiency, as well as to inefficient investments in market forecasting. They also argued, based on results from Maskin and Riley, ${ }^{28}$ that:

Inefficiencies will not be a consequence only of forecasting errors if bidders differ substantially and consistently in their relative marginal costs. In that case, occasional inefficient outcomes are a consequence of rational strategic bidding. For example, if there are two bidders with uncertain costs... and one is known to have lower costs than the other on average, the bidder likely to have higher costs will rationally bid less aggressively ... than the bidder with lower costs .... The consequence will be that the disadvantaged bidder will be called on to supply too often, because it will have submitted a lower bid in some instances in which it has higher costs than its more efficient rival.

$\mathrm{S}$ ince Kahn et al. (2000) do not specify a model, it is difficult to evaluate all of their claims. In particular, it is not always made clear what is meant by a "competitive electricity market." ${ }^{29}$ The argument taken from Maskin and Riley (2000) is slightly easier to place in context, however. Maskin and Riley show that in a singleunit auction with two bidders and cost or valuation asymmetries, in a discriminatory auction lowvaluation types might be induced to bid more aggressively than high-valuation types, and hence win the auction even when it is inefficient for them to do so.
Nevertheless, the discriminatory auction still yields higher (expected) revenues for the seller-or lower prices for the buyer in a procurement auctionand so might be preferred to the uniform auction on those grounds. This is somewhat similar in spirit to our demonstration that the discriminatory auction may result in higher-cost firms

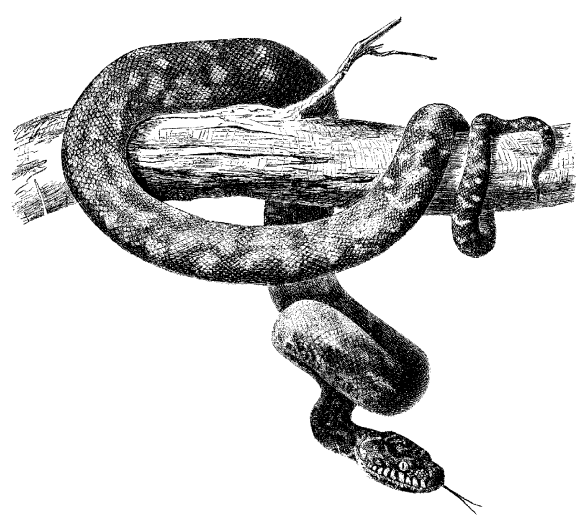

producing too often when mixed strategies are played, but yield lower average prices than the uniform auction. ${ }^{30}$

Maskin and Riley's result, however, comes from a singleunit auction with two competing buyers, in which the source of the inefficiency is incomplete information concerning the buyers' valuations. Our result, on the other hand, comes from a multiunit auction model in which information is complete and the source of the suppliers' market power is a tight demand/capacity balance. The Maskin and Riley result might be viewed as providing an efficiency rationale for preferring the uniform to the discriminatory auction even in the absence of capacity constraints, given the right kind of cost asymmetries and incomplete information. However, if the discriminatory auction results in lower expected prices, the welfare ranking of the two auctions will remain ambiguous. Indeed, the Vickrey auction would appear to dominate the two other auction formats in this setting, which leads us to our final topic in this article.

\section{Vickrey Electricity Auctions}

Although much recommended by economists, Vickrey auctions have rarely been applied in practice, at least in multi-unit settings. ${ }^{31}$ The fundamental insight of Vickrey ${ }^{32}$ was that by making the price received by a bidder independent of its own offer price, marginal cost bidding can be induced as a weakly dominant strategy. Von der Fehr and Harbord (1993) considered a version of a Vickrey auction in which each supplier is paid a price for each unit accepted by the auctioneer determined by the intersection of the demand curve with the "residual" supply curve obtained by subtracting the higher-priced units of that supplier. A supplier can then influence its own payoff only to the extent that its bids affect the probability of being dispatched. Since a supplier will prefer to be operating for all realizations of demand when its payoff is positive, and will prefer not to operate 
whenever its payoff is negative, offering to supply at a price equal to marginal cost becomes a weakly dominant strategy.

$A \begin{aligned} & \text { n important feature of } \\ & \text { Vickrey auctions for elec- }\end{aligned}$ tricity is that there may not exist any excess supply when we remove units of a given supplier, i.e., the intersection of the residual supply curve with the demand curve may be empty. When this occurs a "reserve price" must be defined. If demand is perfectly inelastic, the reserve price is given by consumers' common maximum willingness to pay. For downward sloping demand curves, the reserve price is the point on the demand curve corresponding to consumers' marginal willingness to pay for that unit. This is a simple version of the Vickrey auctions with reserve pricing considered by Ausubel and Cramton (1999).

Krishna and Tranaes (1999) and Hobbs, Rothkopf, and Hyde ${ }^{33}$ have analyzed Clark-GrovesVickrey mechanisms for electricity markets in which each supplier is paid its own bid for each unit of capacity accepted, plus the improvement in social welfare that results from its bid (i.e., the cost savings to the auctioneer). This formulation is essentially equivalent to the multi-unit Vickrey auction. However, in both of these analyses it is assumed that there is always sufficient excess supply, when the capacity of single supplier is removed from the system, to define this cost saving from the rejected bids of the other suppli- ers. Hence, neither paper considers what happens when bidders are large and reserve pricing is required. ${ }^{34}$

$\prod$ he key difficulty with a without reserve pricing, is that the auctioneer's revenues and payments will typically not balance, i.e., the auctioneer will run a deficit. ${ }^{35}$ This feature of the Vickrey auction is well-known, and a general characteristic of optimal incentive-compatible revelation mechanisms. In order to induce the truthful revelation of private information, agents must be offered a positive informational rent. Payment of this rent must come from alternative (non-distorting) sources if the efficiency of the market allocation is to be maintained. When demand is price-inelastic this problem is easily solved, as the market price can include a markup to cover informational rents without distorting efficiency.
With downward sloping demand on the other hand, non-distorting payments from other sources, e.g., lump-sum taxes levied on market participants, may be required.

Another problem with a Vickrey auction (c.f. Hobbs et al., 2000) is that, like the discriminatory auction, it does not define a market-clearing price, and such a price may be required to reconcile deviations from agreed upon forward transactions. ${ }^{36}$ Determining a price for such purposes has proved both difficult, and controversial, for the U.K. regulatory authorities. ${ }^{37}$

\section{Conclusion}

The recent regulatory debates over discriminatory versus uniform-price auctions in the U.K., California and elsewhere have revealed an incomplete understanding of the limitations of some popular auction models

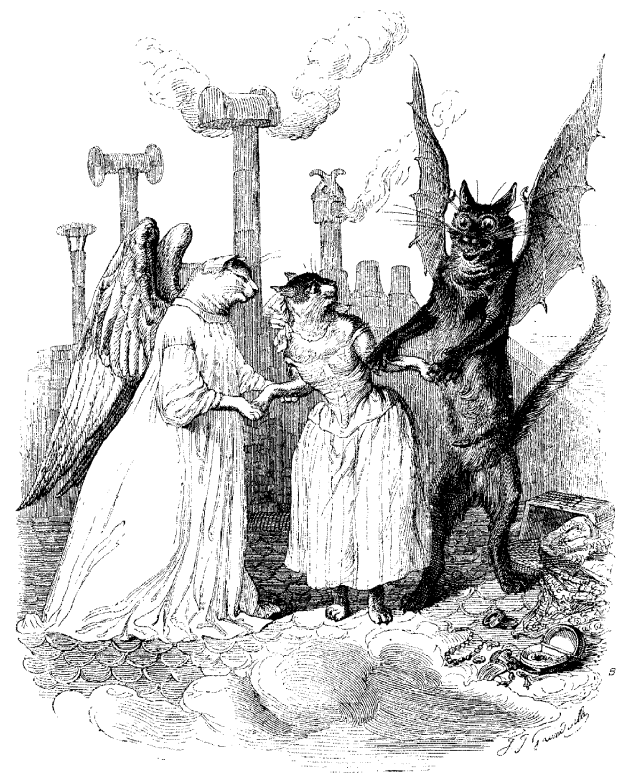

The recent debates have revealed an incomplete understanding of what happens in real-world markets. 
when applied to real-world electricity markets. Arguments in favor of discriminatory auctions appear to come largely from analyses of share auction or supply function models, which are of dubious relevance to any existing electricity market, for the reasons described in this article. Although Vickrey auctions are frequently recommended by economists, they have been largely ignored in these debates, and subject to too little analysis.

$\mathrm{T}$ his article has described the approach that we believe should be taken to analyzing these issues. In Fabra, von der Fehr, and Harbord (2002) we used a discrete, multi-unit auction model to compare uniform, discriminatory, and Vickrey auctions for electricity under a variety of assumptions. We found that the welfare ranking of the different auctions is inherently ambiguous. An understanding of the shortcomings of continuous auction models for diagnosing competition problems in real-world electricity markets may help to prevent expensive reform processes from being undertaken in future which hold out little prospect of real improvements in market performance.

\section{Endnotes:}

1. See Office of Gas and Electricity Markets (OFGEM), The New Electricity Trading Arrangements, Vol. 1, Birmingham, 1999. David Harbord and Chris McCoy, Mis-Designing the Electricity Market, EUROPEAN COMPETITION LAW REV., 2000, at 258-260, discuss the auction reforms in England and Wales, and are critical of the reasoning of the U.K. regulatory authorities. OFGEM, The New Electricity Trading Arrangements: A Review of the First Three Months, Birmingham, 2001, nevertheless claims that its objectives have been achieved. Frontier Economics, Random Wobbles in the Balancing Mechanism? An Assessment of NETA in Action," Aug. 2001, takes a different view of the evidence.

2. See Alfred Kahn, Peter Cramton, Robert Porter, and Richard Tabors,

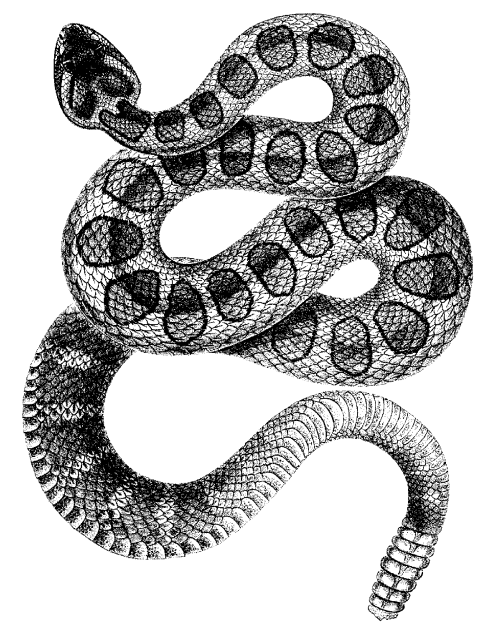

Uniform Pricing or Pay-As-Bid Pricing: A Dilemma for California and Beyond, ELEC. J., 2001, at 70-79, and Stephen Rassenti, Vernon Smith, and Bart Wilson, Discriminatory Price Auctions in Electricity Markets: Low Volatility at the Expense of High Price Levels, Department of Economics, University of Arizona, 2001, for discussions.

3. See Larry Ausubel and Peter Cramton, Demand Reduction and Inefficiency in Multi-unit Auctions, Department of Economics, University of Maryland, 1998, and Ken Binmore and Joe Swierzbinski, Treasury Auctions: Uniform or Discriminatory? Rev. Econ. Design, 2000, 5, at 387410 , for the theory and empirical evidence.

4. Catherine Wolfram, Electricity Markets: Should the Rest of the World Adopt the U.K. Reforms? Regulation, 1999, 22, at $48-53$.

5. Rassenti, Smith, and Wilson, supra note 2 .
6. Guilo Federico and David Rahman, Bidding in an Electricity Pay-As-Bid Auction, Working Paper No. 2001 W5, Nuffield College, Oxford, 2001.

7. Paul Klemperer, What Really Matters in Auction Design, mimeo, Nuffield College, Oxford, 2001.

8. Kahn, Cramton, Porter, and Tabors, supra note 2.

9. See Robert Wilson, Architecture of Power Markets, Graduate School of Business, Stanford University, 2001, for a discussion.

10. Nils-Henrik von der Fehr and David Harbord, Spot Market Competition in the U.K. Electricity Industry, ECON. J., 1993, 103, at 531-546, studied Vickrey auctions with reserve prices in electricity markets for some extremely simple cases. Larry Ausubel and Peter Cramton, Vickrey Auctions with Reserve Pricing, Department of Economics, University of Maryland, 1999, provide a more general framework.

11. Natalia Fabra, Nils-Henrik von der Fehr, and David Harbord, Designing Electricity Auctions: Uniform, Discriminatory and Vickrey, mimeo, Institut D'Économie Industrielle at Université de Toulouse, and University of Oslo, 2002. These simplifications allowed for direct comparisons in many cases.

12. For example, a weighted average of consumer and producer surplus.

13. In Australia, and in the original England and Wales market, bids are submitted daily, while in Argentina bids last for six months. See Anton García-Díaz and Pedro Marín, Strategic Bidding in Electricity Pools with ShortLived Bids: An Application to the Spanish Electricity Market, CEPR Discussion Paper 2567, 2002, for the importance of this distinction.

14. This observation was first made in Richard Green and David Newbery, Competition in the British Electricity Spot Market, J. Pol. Econ., 1992, 100, at 929-53.

15. Robert Wilson, Auctions of Shares, Q. J. Econ., 1979, 93, at 675-689, Kerry Back and Jamie Zender, Auctions of Divisible Goods: On the Rationale for the Treasury Experiment, Rev. FIN. STUD., 1993, 6 (4), at 733-764, Paul Klemperer 
and Margaret Meyer, Supply Function Equilibria in Oligopoly under Uncertainty, ECONOMETRICA, 1989, 57, at 1,243-1,277, Green and Newbery (1992), supra note 14. See also Richard Green, Increasing Competition in the British Electricity Spot Market, J. IND. ECON., 1996, XLIV, at 205-216, Federico and Rahman (2001), supra note 6, Kalai Krishna and Torben Tranaes, Providing Uncertain Quantities Efficiently: Theory and Applications to Electricity Deregulation, mimeo, NBER, 1999, and Ross Baldick and William Hogan, Capacity Constrained Supply Function Equilibrium Models of Electricity Markets, POWER Working Paper 089, University of California Energy Institute, 2001.

16. See also García-Díaz and Marín (2002) op. cit., Anton García-Díaz, Uniform-Price Versus Pay Your Bid Multi-Unit Auctions under Complete Information, mimeo, Universidad Carlos III, 2000, Natalia Fabra, Tacit Collusion in Repeated Auctions: Uniform-Price Versus Discriminatory, mimeo, IDEI, Université de Toulouse, 2002, Claude Crampes and Anna Creti, Price Bids and Capacity Choice in Electricity Markets, mimeo, Institut D'Économie Industrielle, Université de Toulouse, 2001, and Gert Brunekreeft, A MultipleUnit, Multiple-Period Auction in the British Electricity Spot Market, ENERGY ECON., 2001, 23, at 99-118.

17. Paul Klemperer, Why Every Economist Should Learn Some Auction Theory, mimeo, Nuffield College, Oxford, 2000.

18. See Klemperer and Meyer, supra note 15, Section 2, Kerry Back and Jamie Zender, Auctions of Divisible Goods with Endogenous Supply, Working Paper, University of Arizona, 1999, and James Wang, and Jamie Zender, Auctioning Divisible Goods, EcON. THEORY, 2002, 19 (4), at 673-705, for further discussion.

19. Another way of saying this is that, faced with a rival's steep supply function, the incentive to bid aggressively is offset by the large decrease in price required to capture an infinitesimal increment in output. The "price effect" always outweighs the "quantity effect" for units of infinitesimal size.
20. Kjell Nyborg, Underpricing and Market Power in Uniform Price Auctions, mimeo, London Business School, 2001.

21. For an analysis of auctions with both a quantity multiple and a positive tick size, see Nyborg (2001) supra note 20, Section 4.2.

22. See Christine Archibald and Paul Malvey, Uniform-Price Auctions: Update of the Treasury Experience, Working Paper, U.S. Treasury, 1998, and Gregory Belzer and Vincent Reinhart, Some Evidence on Bid Sharing and the

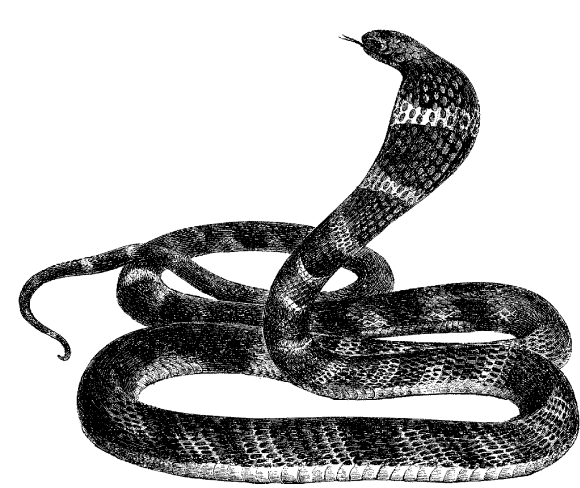

Use of Information in the U.S. Treasury's Auction Experiment, Working Paper, Board of Governors of the Federal Reserve System, 1996.

23. See Back and Zender, supra note 15, and Nyborg, supra note 20, for further analysis of this model.

24. More formally, first-order conditions must now hold over an entire interval of possible equilibrium prices, corresponding to different realizations of demand, rather than just at a single point, as in the non-stochastic model. With unbounded uncertainty Klemperer and Meyer, supra note 15, show that equilibria in the supply function model are unique.

25. See Nyborg, supra note 20, Sections 3 and 4 , for an exposition of this result.

26. See von der Fehr and Harbord, supra note 10, Proposition 4, and Fabra, von der Fehr and Harbord, supra note 11, Section 6.

27. See also Wolfram (1999), op. cit.
28. Eric Maskin and John Riley, Asymmetric Auctions, Rev. ECON. STUD., 2001,67 , at $413-438$.

29. It is certainly not true in our models that in a competitive framework each firm will bid in its own marginal cost in the uniform auction. Indeed, the uniform and discriminatory auctions are strategically equivalent in this setting.

30. Fabra, von der Fehr and Harbord, supra note 11, Section 4.2.

31. See Michael Rothkopf, Thomas Teisberg, and Edward Kahn, Why Are Vickrey Auctions Rare? J. POL. ECON., 1990, 98 (1), at 94-109, for a discussion. Ascending (English) auctions, such as those used to sell antiques and rare paintings, are of course equivalent to single-unit Vickrey auctions, c.f. Binmore and Swierbinski, supra note 3.

32. William Vickrey, Counterspeculation, Auctions, and Competitive Sealed Tenders, J. FIN., 1961, 16, at 8-37.

33. Benjamin Hobbs, Michael Rothkopf, Laurel Hyde, and Richard O'Neill, Evaluation of a Truthful Revelation Auction in the Context of Energy Markets with Nonconcave Benefits, J. REG. ECON., 2000, 18, at 5-32.

34. Krishna and Tranaes, supra note 15 , assume continuous supply functions, following Klemperer and Meyer, supra note 15. Hobbs et al. (2000), op. cit., are not explicit on this point. However, the continuity assumption is of no importance when considering Vickrey auctions.

35. Also noted by Hobbs et al., supra note 33 .

36. Peter Cramton and Robert Wilson, A Review of ISO New England's Proposed Market Rules, mimeo, Graduate School of Business, Stanford University, 1998, emphasize the importance of this feature of uniform-price electricity auctions.

37. See Harbord and McCoy, supra note 1, for a discussion. A third muchdiscussed problem with Vickrey auctions, or mechanisms, is their vulnerability to collusion, especially between the sellers and buyers; see Rothkopf et al., supra note 31, and Krishna and Tranaes, supra note 15. 